https://doi.org/10.52449/1857-4114.2020.36-2.10

CZU: 159.9+796.012:797.2-053.2

\title{
THEORETICAL ASPECTS REGARDING THE PARTICULARITIES OF THE DEVELOPMENT OF PSYCHOMOTRICS IN CHILDREN AGED 7-10 YEARS DURING SWIMMING LESSONS
}

\author{
Ninicu Alina ${ }^{1}$ \\ Goncearuc Svetlana ${ }^{2}$ \\ ${ }^{1}$ Specialised Sports Swimming School, Chisinau, Republic of Moldova \\ ${ }^{2}$ State University of Physical Education and Sport, Chisinau, Republic of Moldova
}

\begin{abstract}
The research reflects the theoretical analysis of the references regarding the concept of psychomotor skills. The structure and the content of psychomotor skills are determined. It was made a sociological study that reflects the opinions of physical education teachers and swimming coaches, regarding the level of knowledge of the theoretical aspects of psychomotor skills and the particularities of its development on 7-10 year-old children during swimming lessons.

Swimming is a wonderful means of harmonious physical development and strengthening the health of children. He very well develops the muscles of the whole body, strengthens the heart, lungs, cleans the skin. In the case of many diseases swimming is used as a means of treatment.
\end{abstract}

Keywords: psychomotor, psychomotor abilities, children aged 7-10 years, the means of swimming.

The actuality of the subject. The concept of psychomotor skills has crystallized over the past centuries, as a result of the physiological and psychophysiological research of scientists.

R. Decart in the seventeenth century created the basis of the reflection theory, proving that the reason of movement can serve an extreme factor, which has an impact on the sense organs. The English scientist C. Bell found that, in addition to the motor nerves, which are located near the muscles, there are also the sensory nerves. I. Secenov argued the reflective origin of voluntary movements and, at the same time, discovered the role of muscle sensitivity for coordinating movements in space and time and its connection with auditory and visual sensations. S. Rubeistein stated that the psyche do not only determines movement, but also manifests itself in motor reactions. V. Platonov said that psychomotority is the objectification of all forms of mental inclusion in sensorimotor, ideomotor and emotional-motor reactions and acts. E. Fleichman, R. Cattell and K. Pawlik developed the term psychomotor, including a greater number of psychomotor factors.

The aim of the research is to identify some particularities of development of psychomotor skills in children aged 7-10 years by swimming.

The objectives. The objectives of the research were: the analysis of theoretical approaches to the concept of psychomotor skills; establishing the content and areas of reference for the development of psychomotor skills in children aged $7-10$ by swimming; elaboration and implementation of the sociological research program of the particularities of psychomotor development of children aged 7-10 through the means of swimming;

The methodology and organization of the research consists in the theoretical analysis and synthesis of references; sociological research methods. 


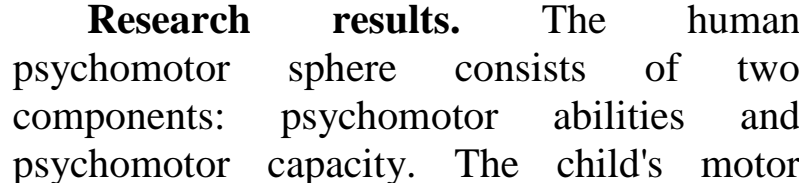
activity develops motor skills, strengthens the musculoskeletal system. Swimming lessons develop coordination, rhythmic movements, make all the muscle groups of the body work, which contributes to the harmonious development of the muscular system of 7-yearold children [1]. A special period in the development of both the motor analyzer and the higher psychic functions is the low school age. "Possession of psychomotor skills has a considerable impact on children's learning, including the acquisition of notions. Certain physical skills are the necessary condition for mastering many objects of study" [2]. As N.D. Levitov remarks, at no other school age, learning activity is not so closely related to health and physical development as at a young age. Based on the conception of E.P. Iliin, we analyze the particularities of psychomotor skills, taking into account the motor abilities that mean "such psychological and psychophysiological features, which ensure successful motor activity" [3, p. 5], and highlight the group of psychomotor qualities, especially appreciable in achieving success of swimming lessons in school. This group includes coordinating abilities: maintaining body balance and controlling static and dynamic tremor; floatability proprioceptive functions, which include the appreciation, measurement, reproduction and differentiation of spatial, force and time parameters of movements, long and short duration memory. As efficient properties of physical activity, especially swimming, we consider the following characteristics of movements and reactions: the accuracy of movements in accordance with the given trajectory and direction; coordination of movement-ability to overcome excess levels of freedom of the mobile organ, i.e. its transformation into a directed system [4]; rhythm of movements periodic repetition of movements (in terms of: spatial, temporal, force); coordination of movements - uniform, uninterrupted development of a movement; accuracy of memorization and reproduction - the ability to reproduce information without distorting it; the correctness of the interpretation of the coordination of movements [4]. Characterizing the period of motor development in students aged 7 to 10 years, N.A. Bernstein notes that the means of constituting the child's movement consist of two components - force and accuracy, which develop gradually [5]. Based on the development of the spatial field, especially of the pyramidal sublevel, related to the cortical levels, the scientist considers that this age is the most opportune to start initiation and training. It should be mentioned that the spatial field achieves the coordination and the exact objective perception of the environment by training all the sense organs, especially the optical afference, based on the previous experience preserved in memory. This level determines the beginning and the end, the opportunity, the precision and the accuracy of the movement [5]. The oldest and most basic movements of the level of space are those of locomotion, which provide for the movement of the body in space. N. A. Bernstein wrote: "Typical movements of the level of the space field always lead from somewhere and for something." This aphoristic characteristic indicates that such movements have topological and metrical parameters, which are always directed towards the goal, lead to a certain final result, and the movements are aware [5]. The elementary form of spatial orientation develops in children as early as infancy. With the onset of school, the volume of this knowledge expands considerably, increasing the requirements for their level of differentiation and the degree of abstraction and generalization of spatial criteria and relationships. The particularities of the perception and representations of space in beginner students are reflected in a series of researches $[6,7,5,8,4]$. 
As noted, at 7 years of age, there is still insufficient differentiation of movements. The pupils in the primary classes can take the necessary picture, but there are also children who, due to the poor differentiation of the movements, cannot perform specific tasks of coordination. An important role in the interpretation of swimming movements is given to motor memory, i.e. to memorize the movements and systems of these movements. V. D. Shadrikov divided the individual differences of memory into particularities, which can be delimited as criteria of memory productivity: memory volume - the numerical index of productivity of mnemonic processes (the volume of material that can be reproduced directly after a unitary perception); accuracy of memorization and reproduction; the ability to reproduce information without distorting it; memorization durability; maximum activity of long-term storage of stored material; memorization speed; the time required for full storage of the material. All memory skills are important for pupils to practice swimming. By skill we mean the skill gained as a result of learning and repetition and which allows you to solve tasks with accuracy and high speed.

The process of forming motor skills is conventionally divided into stages, the number of which is different for different authors. We consider more appropriate the conception of $\mathrm{V}$. D. Maznicenco and E. P. Iliin, who examines five stages: The first stage is related to the formation in students of the visual representation about movements or combinations of movements. The main channels for obtaining information are visual (demonstration of movements) and auditory (teacher's explanation). The second stage is related to the initial stage of execution of the learned movement. It is characterized by a large irradiation of excitation of the nerve centers, insufficient internal braking and disorder of the nervous system. The third stage is characterized by the concentration of excitation in those nerve centers, which is needed to direct the given motor act. In this way the formation of the dynamic stereotype begins. The fourth stage is to automate the action. The movement technique is performed stably. The fifth stage consists in the formation of higher order skills, which are characterized by a free variable technique.

In order to facilitate both the understanding of the nature of the movement skill and the creation of the learning schedule of such skills, it is necessary to examine the type of tasks applicable to these skills. The elaboration of psychomotor tasks compared to cognitive tasks is just beginning, but they are already weighted, a fact elucidated by Harrovv [9].

\section{Components of psychomotor skills.}

According to M. Epuran (2010), the components of psychomotor skills are: body scheme; segmental and general dynamic coordination; laterality; static coordination balance; perceptual-motor coordination (perception of space, rhythm and own movements); speed of movements; ideomotricity as a dynamic synthesis of the body scheme and of the perceptual-motor coordinations with the motor task. E.A. Fleishman (quoted by Epuran, 1976), gives the following characteristics of the field of psychomotor skills: precision of control, the ability to perform appropriate movements, putting into action important muscle groups; multi-segmental coordination, i.e. the possibility of combining the action of several body segments; choosing the answer, the possibility to select the desired answer; simple and fast reaction time; speed of movement, especially of the arms; the ability to appreciate the speed of movement of an object; manual dexterity, the possibility of handling very small objects; stability of the arm and hand during an exercise; "Tapping", i.e. the possibility of quick and accurate execution of wrist movements; the ability to make a particular oculo-manual adjustment by sight. L. Picq and P. Vayer realized the most schematic structure of motor function. They distinguish three types of activity in children: 1) basic 
motor behaviors, which include: oculo-motor coordination; static and dynamic balance; general dynamic coordination; 2) neuromotor behaviors, which include proprioceptivity and muscle tone; 3) perceptual-motor behaviors and structures: body scheme; laterality; spatial-temporal orientation.

According to Bucher, the acquisition of the body scheme is obtained in two stages:

I. The overall accuracy of the body, its unity, its position in space. It is a very important stage, often underestimated, which allows, through the experience of the body as a whole, the global and immediate consideration of perceptions. In addition, it gives back to the body the privileged object of a specific interest, of a seen and valued experience, and all the more so as its image is specified through the role of language and internalization. All these are clearly favorable if they are done in a reeducational environment, which allows the child to abandon his defense systems to dedicate himself to the experience of his own body and his own impressions. The exercise will be provided by a time of mental preparation, which will allow the child to respect and assimilate the given note and to establish the connection perceptionrepresentation; the record and the way of conducting the exercise must provoke the sensation of bodily pleasure, the first stage in reaching the bodily parts. The same goal is achieved concretely by putting the child in "bodily situations" (specified verbally), from which we exemplify: a) body positions (standing, sitting, lying down); each of them must correspond to a clear verbal image, with examples used in everyday life. b) body movements, with which the child becomes aware through: the contrast movement - stop, time variations of movements, changes of ground support, possible variations of running, four-legged walking, jumping, change of movements in a coded order.

II. The first spatial relationships, which allow the child to differentiate the positions and movements of the limbs separately; this goal is achieved starting from the motor experiences during which the proprioceptive and exteroceptive elements will be matched; this explains the importance of the fact that, through language and the use of the mirror, the child assimilates the: data regarding the body in space (forward, backward), main body references (segments, joints), relative positions of segments in relation to the body.

The theoretical study guided us in the elaboration of a questionnaire in order to research the knowledge by swimming teachers-coaches of the concept of psychomotor skills. The sociological research was organized on a sample of 20 coaches and physical education teachers from the Specialized Swimming Sports School, Chisinau, Specialized Swimming Sports School no. 11, Theoretical Sports High School no. 2, Sports School no. 8, Chisinau. In sociological research, $40 \%$ were women and $60 \%$ were men between the ages of 30 and 65 . Most respondents actively participate in competitions with children aged 7-10, the competitions being from the first city to the Championship of the Republic of Moldova. In order to identify knowledge of the concept, abilities and components of psychomotor skills in the learning and training of children aged 7-10, psychomotor intelligence in swimming lessons and requirements for exercises that can develop pupils' psychomotor skills, we conducted a study by questioning sociological analysis of coaches.

We present the results of the questionnaire in the following graphs. The first question was general "Do you know at what age the child should start swimming?". As we have noticed, $70 \%$ of coaches know at what age children should start swimming according to GD no. 31 of 30-01-2019. But at 30\% opinions are divided, given that $10 \%$ believe that children should start training at an early age, and 20\% believe that learning to swim should start later, to extend the term of sports swimmer's career. 


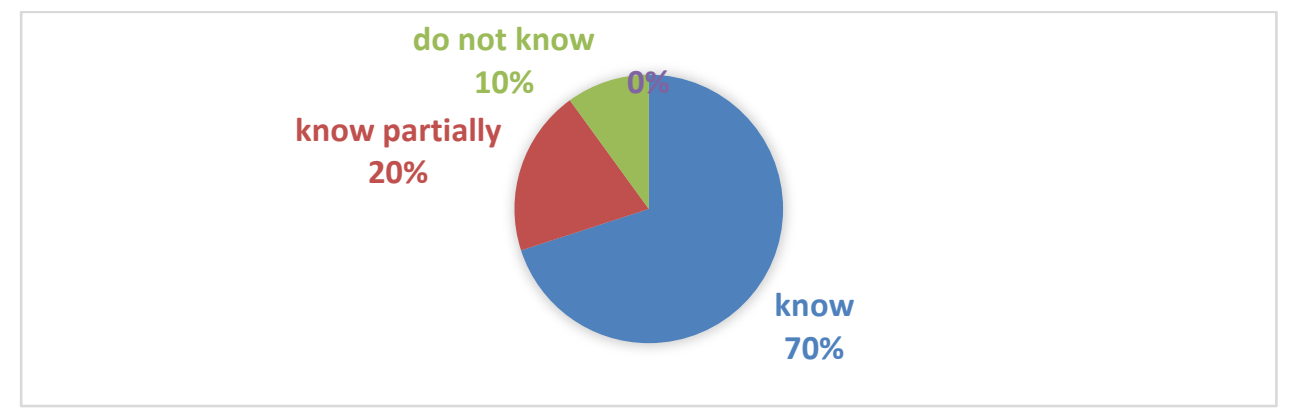

Fig.1. Teachers' opinions on the age at which children start swimming

On the second topic, "Do you know what changes occur in neurocerebral psychomotor skills in children aged 7-10?", We found that $50 \%$ of coaches do not know what changes may occur at this age in neurocerebral psychomotor skills, $40 \%$ know partially and only $10 \%$ know well. This question emphasizes how important it is to know the exact neurocerebral changes at this age, in order to know what qualities need to be trained and developed in children at the early stage of learning to swim.

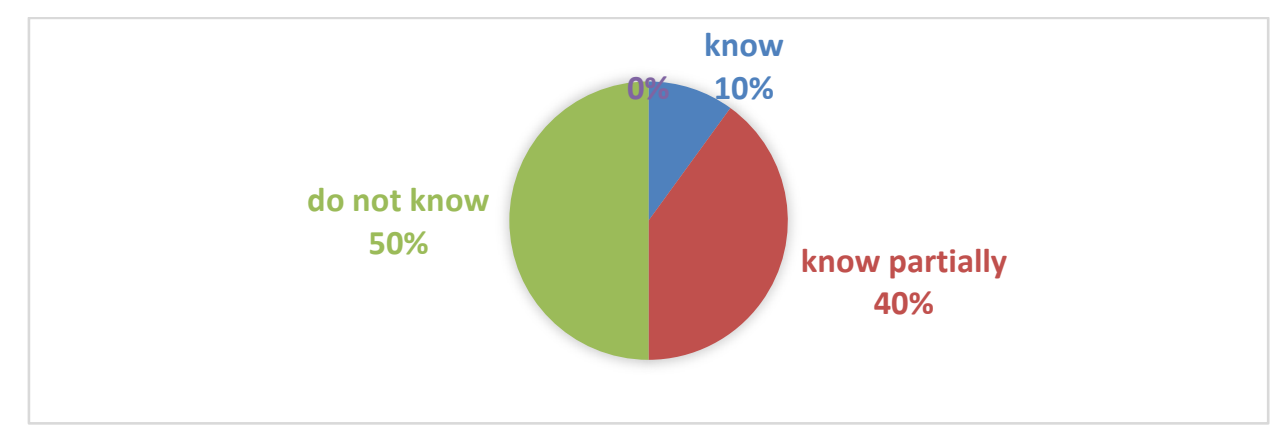

Fig. 2. Coaches' opinions on changes in neurocerebral psychomotor skills in children aged 7-10 years

The third question was formulated as questionnaires completed by the coaches, we follows: "Do you know what self-regulation skills are characteristic of the 7-10 year-old found that $70 \%$ of the coaching teachers know, child?". Following the analysis of the $20 \%$ know partially and $10 \%$ do not know.

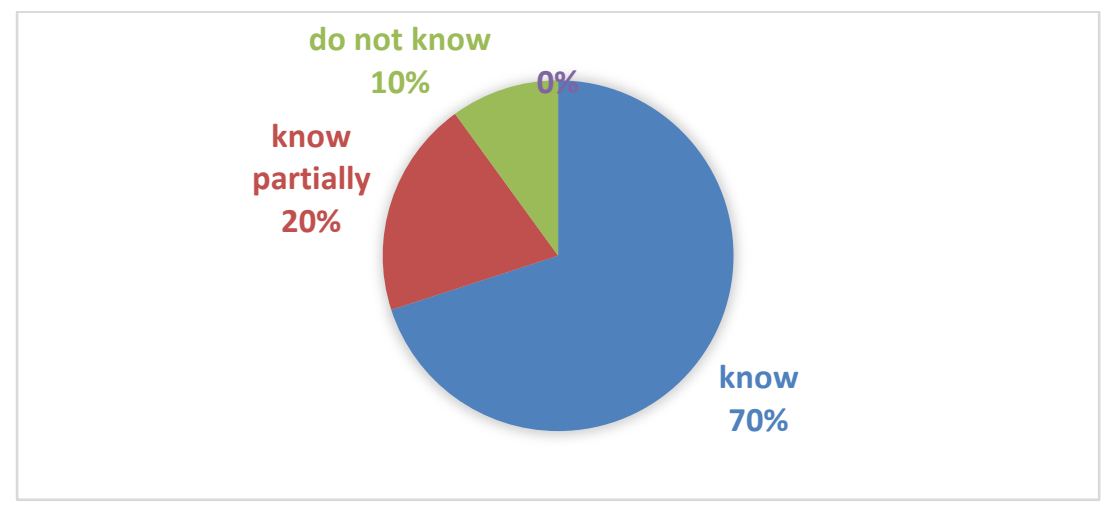

Fig. 3. Coaches' opinions on knowing the self-regulation skills characteristic of children aged 7-10 
The fourth question was: "Do you know what the concept of psychomotor skills involves?". The following results were recorded here: $50 \%$ know, $40 \%$ partially know, $10 \%$ do not know.

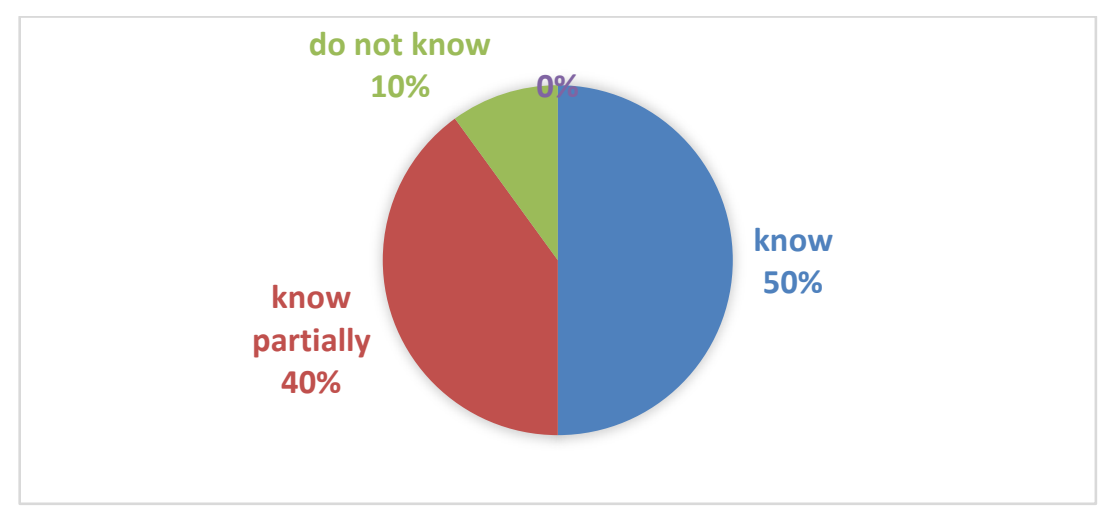

Fig.4. Coaches' opinions on knowing the concept of psychomotor skills

The fifth question was worded as follows: "Do you know what the term psychomotor abilities implies?". Based on the answers in the questionnaires, it can be seen that $60 \%$ know, $30 \%$ partially know and $10 \%$ do not know.

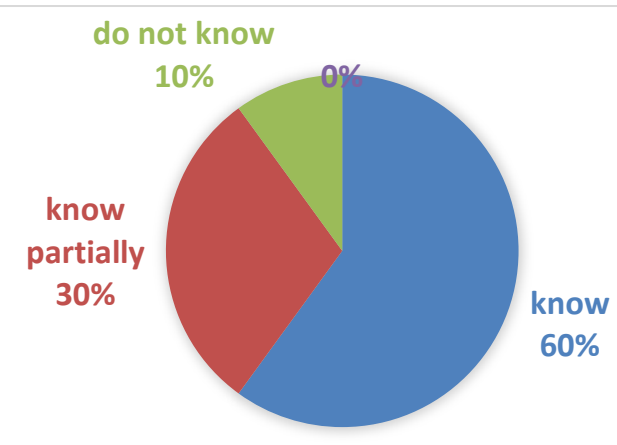

Fig. 5. The opinions of the coaches regarding the knowledge of the term psychomotor abilities

The essence of the next question was: "Do you know what the components of psychomotor skills are?", Here the answers deviated again - 70\% know, 20\% know partially, $10 \%$ do not know.

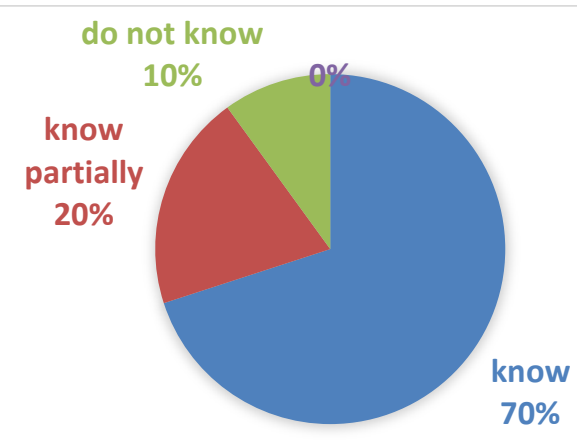

Fig.6. Coaches' opinions on knowing the components of psychomotor skills 
On the seventh topic, "Do you know what motor intelligence is expressed by?", Most answered in the affirmative - $80 \%$ know, $20 \%$ know partially, $0 \%$ do not know.

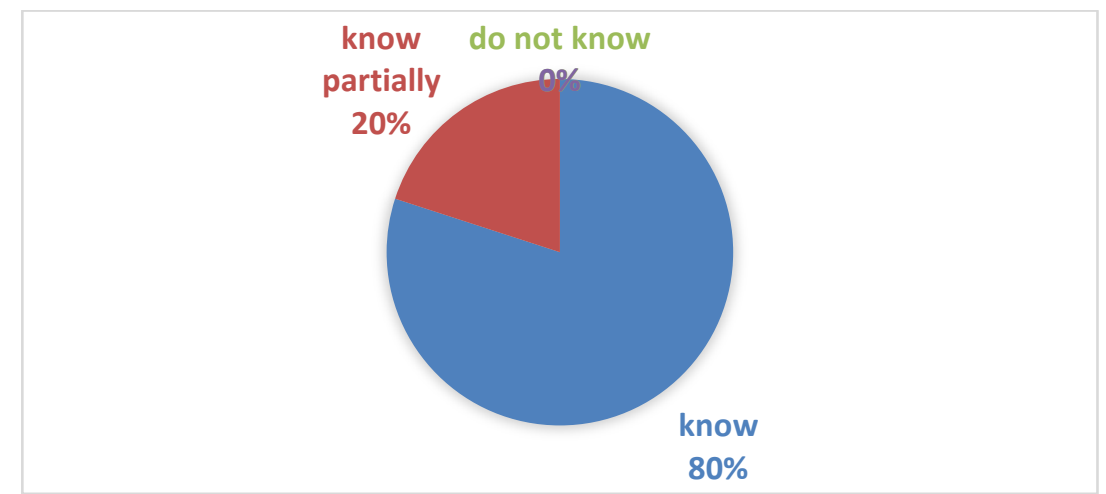

Fig.7. Coaches' opinions on knowledge of motor intelligence

To the question "Do you know the notion of ambidexterity?", The differences between the answers were practically not: $80 \%$ know, $15 \%$ know partially, $5 \%$ do not know.

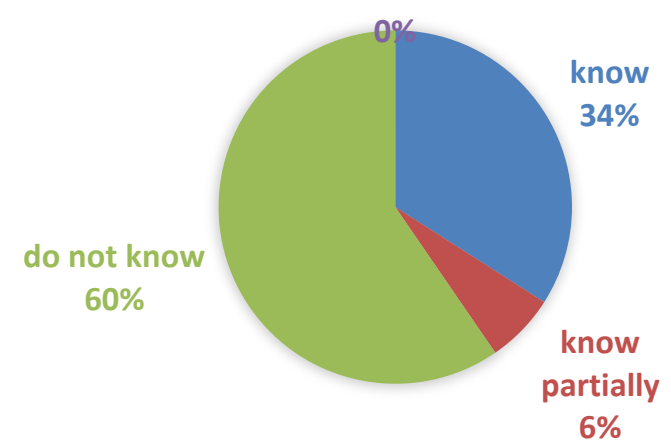

Fig.8. Coaches' opinions on knowing the notion of ambidexterity

The new topic, "Do you know what can influence the ambidexterity of the 7-10 year old child who practices swimming?", gave coaches headaches: $40 \%$ know, $40 \%$ know partially, $20 \%$ do not know.

Fig.9. Coaches' opinions on the influence of the ambidexterity of the 7-10 year old child who practices swimming 
On topic ten, "Do you know what are the basic requirements in selecting exercise for children aged 7-10?", The opinions were diverse: $50 \%$ know, $40 \%$ partially know, $10 \%$ do not know.

\section{Fig.10. Coaches' opinions on the basic requirements in the selection of physical exercises for} children aged 7-10

Conclusions. The analysis of the literature and the study demonstrated the commitment of researchers and practitioners to the issue of developing children's motor skills in the lesson of physical education and swimming training. Swimming teachers and coaches have fairly balanced views on the need for psychomotor development of children in the initial stage of training in the process of swimming lessons, but indicate that they have modest knowledge of their use in practice.

\section{References:}

1. Ачиева Н.Е., Коноплева А.Н., Кишев А.З. (2015). Плавание и подвижные игры как средства развития общей моторики детей 6-7 лет. В: Международньй научноиследовательский журнал. ISSN 2227-6017 (ONLINE), ISSN 2303-9868 (PRINT), DOI: 10.18454/IRJ.2227-6017ПИ № ФС 77 - 51217.

2. Левитов Н. Д. (1964). Детская и педагогичнеская психология. М.: Просвещение. 478 c.

3. Ильин Е. П. (1983). Психофизиология физического воспитания: Факторы, влияющие на эффективность спортивной деятельности. Учеб. пособие для студентов пед. ин-тов по спец. - 2114. Физ. воспитание. Москва: Просвещение. 223 с.

4. Шадриков В. Д. (1996). Психология деятельности и способности человека. Учеб. пособие. Москва: Издательская корпорация Логос. 320 с. $228 \mathrm{c}$.

5. Бернштейн Н. А. (1991). О ловкости и ее развитии. Москва: Физкультура и спорт.

6. Ананьев Б. Г. (1955). Пространственное различение. Ленинград: Изд. ЛГУ. 186 с.

7. Галкина О. И. (1961). Развитие пространственных представлений у детей в начальной школе. Москва: Изд. АПН РСФСР. 99 с.

8. Сорокун П. А. (1969). Формирование и развитие пространственных представлений у учащихся. В кн.: Восприятие пространства и времени. Л.: Наука, с. 48-49.

9. Harrovv A. A. Taxonomy of the motor Domain. N. Y., 1972.

10. Epuran M., Holdevici Ir., Toniță F. (2008). Psihologia sportului de performanță. București: Editura FEST. 468 p. 